\title{
MACROECONOMIC DRIVERS OF NON-PERFORMING LOANS: A META-REGRESSION ANALYSIS
}

\author{
Martin Macháček, Aleš Melecký, Monika Šulganová*
}

\begin{abstract}
Common exposure to macroeconomic risk factors across financial institutions is a source of a systemic risk that influences quality of banks' loan portfolios. This paper focuses on the growing literature on credit risk determinants. The aim of the paper is to provide more general information on effects of macroeconomic drivers with the use of quantitative metaanalytic techniques. We consider five of the most common macroeconomic determinants of non-performing loans ratio. The meta-regression results suggest that there are some significant differences among studies, which could be identified. For instance, data specification, estimation method, number of countries and observations included in the model play a significant role. In some cases, e.g. inflation and exchange rate, the size of the effects presented in journals with impact factor are significantly different from other types of studies included in the analysis. The sub-sample analysis mostly confirms meta-regressions results.
\end{abstract}

Keywords: aggregate credit risk, macroeconomic credit risk drivers, non-performing loans ratio, meta-analysis, sub-samples analysis

JEL Classification: G21, C20, E44

\section{Introduction}

The monitoring of credit risk is an important part of macroprudential analysis, which focuses on the evaluation of systemic risk. Systemic risk is considered to be endogenous due to common exposures of financial institutions to macroeconomic risk factors and related interactions between the real economy and financial systems (Borio, 2003). The aim of the paper is to provide more general information on the effects of macroeconomic drivers of aggregate credit risk and to identify key differences among studies. The aim is fulfilled by employing meta-analyses of selected macroeconomic credit risk drivers. Although, there are several ways how to measure aggregate credit risk (see Section 2), we have focused only on the studies employing non-performing loans ratio (NPLR) as an indicator of credit

* Martin Macháček, Department of Economics, VSB-Technical University of Ostrava, Ostrava, Czech Republic (martin.machacek@vsb.cz);

Aleš Melecký, Department of Economics, VSB-Technical University of Ostrava, Ostrava, Czech Republic (ales.melecky@vsb.cz);

Monika Šulganová, Department of Economics, VSB-Technical University of Ostrava, Ostrava, Czech Republic (monika.sulganova@vsb.cz).

We would like to thank participants of INTCESS15 Conference, which was held in Istanbul in February 2015, for their comments on previous draft of the paper.

This work has been supported by the Czech Science Foundation under Grant No.16-13784S; Operational Programme Education for Competitiveness and co-financed by the European Social Fund under Grant No. CZ.1.07/2.3.00/30.0016 and Grant No. CZ.1.07/2.3.00/20.0296. 
risk. This indicator was selected because within the identified studies, NPLR is the most commonly used indicator approximating aggregate credit risk.

The macroeconomic credit risk drivers included in our analysis are the most often used macroeconomic determinants presented in the surveyed studies. More specifically, we consider real economic growth (REG), interest rate (IR), inflation (INFL), exchange rate (ER) and unemployment (UNP). The general effects of selected drivers are calculated as the weighted averages (WA) of the parameters of respective determinants, which were estimated and published in the empirical studies. The weights of the parameters which represent the precision of estimation, are calculated as an inverse to their standard errors (1/SE), see e.g. Knell and Stix (2005).

Meta-analysis enables researchers to identify publication selectivity (publication bias) to correct inaccurate results caused by misuse and/or misspecification of methodologies or to investigate structural differences in estimated parameters (Havránek and Sedlař́ková, 2014). Meta-analysis can also identify differences among studies (models) and clarify the results which are not uniform according to the empirical literature (e.g. how changes in the price level or exchange rate affect aggregate credit risk). This method has been suggested as a potentially more powerful compared to the "standard" literature surveys (see Cuaresma et al., 2011). Further, meta-analysis allows us to analyse possible factors which may influence estimated results (e.g. data definition or inclusion of specific group of countries). We employed the weighted least squares (WLS) approach to identify the differences among studies.

The rest of the paper is organized as follows. Section 2 describes surveyed studies, their main characteristics and selection procedure. Section 3 focuses on the effects of macroeconomic drivers on NPLR and provides basic statistical analysis. Section 4 briefly describes meta-regression methodology and defines control variables for the metaregressions. Section 5 presents the results including graphical evaluations, meta-regressions results and sub-sample analysis. The last section concludes.

\section{Surveyed Studies}

We searched various sources in the period from June 2014 to March 2015, e.g. Web of Science (WOS) and Scopus databases or published literature reviews, and tried to find all studies focused on aggregate credit risk, that were regressed on selected macroeconomic determinants: REG, IR, INFL, ER and UNP. Overall, we identified 37 studies $^{1}$ that included 146 models and almost 400 parameter estimates for selected drivers. The inclusion of each study among selected studies required the following conditions to be fulfilled: (i) aggregate

1 The full list of employed studies with their characteristics is available upon request. Besides the studies cited in the text, the following articles were included: Ahmad and Bashir (2013), Alhassan et al. (2014), Babouček and Jančar (2005), Choy (2014), de Bock and Demyanets (2012), Greenidge and Grosvenor (2010), Gremi (2013), Guy and Lowe (2011), Kasselaki and Tagkalakis (2014), Kavkler and Festić (2010), Mancka (2012), Messai and Jouini (2013), Moscone et al. (2014), Saba et al. (2012), Salas and Saurina (2002), Shijaku and Ceca (2011), Shingjergji (2013), Vazquez et al. (2012), Yurdakul (2014), and Zeman and Jurča (2008). 
credit risk is measured as a non-performing loans ratio (or its logarithmic transformation), (ii) at least one of the selected macroeconomic credit risk drivers is included and (iii) the study provides results on $\mathrm{SE}$ or other statistics that enable us to capture the precision of estimations. However, there is a significant amount of studies that do not fulfill these requirements. For example, studies conducted on a disaggregated level (Boss et al., 2009 or Cifter et al., 2009). Further, studies using other indicators of credit risk, i.e. loan loss provisions (see Hoggarth et al., 2005 or Vogiazas and Nikolaidou, 2011), various specifications of default rate (see Bonfim, 2009 or Vuillemey, 2014), indicators based on the inflow of non-performing loans (NPLs, see Marcucci and Quagliariello, 2008 or Bofondi and Ropele, 2011) or loan loss reserves (see Liu and Yang, 2010 or Love and Turk Ariss, 2014).

There is only a limited number of studies that were published prior to the global financial and economic crisis (7 prior to 2008), and the literature has been fast-growing since 2010. Almost two thirds of the selected studies (24) investigate the credit risk of an individual country (either as a time series model or as a bank-level panel data model). The rest of the selected studies (13) use cross-country panel data models. Some of them work with extensive samples of selected countries, e.g. Podpiera (2006), Babihuga (2007) or Buncic and Melecky (2013). Part of the panel data studies is region-specific, see e.g. Jakubík and Reininger (2013) or Škarica (2014) for CESEE countries, Festić et al. (2009) or Novikov (2012) for Baltic States, Espinoza and Prasad (2010) for GCC countries or Castro (2013) for PIIGS countries. According to the frequency of data used, the surveyed studies deal mostly with quarterly data (19) followed by annual data (15), and monthly data (3). Less than half of the selected papers are published in journals indexed in the WOS (11) or Scopus (5). The rest of the studies is published in reviewed journals not indexed in the aforementioned databases, or is available only as a working paper of reputable international institutions (e.g. IMF or BIS) or central banks. Approximately two thirds of the studies (23) employ dynamic model specifications (at least one lag of an explained variable into explanatory variables). In these studies, (NPLs) are treated as persistent and are modelled as a dynamic process.

\section{Effects of Macroeconomic Determinants on NPLR}

Table 1 provides vote counting analysis, which summarizes information about selected credit risk drivers obtained from the surveyed studies. Namely, it reports the number of models with positive and negative parameters of a respective driver. The third row captures the number of models with the estimated coefficients not being reported, i.e. the drivers appear in the model specification but finally they are excluded from the analysis and the coefficients are not presented (mostly due to their statistically non-significant value). The fourth row presents the number of models that do not consider selected credit risk drivers in the model specification. The most frequently incorporated macroeconomic determinant of NPLR is real economic growth (108) followed by interest rate (95).

The empirical evidence on the effect of real economic growth on NPLR is mostly in line with the theoretical assumption (97 negative values) when REG increases the ability of debtors to pay their debts off (e.g. Jiménez and Saurina, 2006; Louzis et al., 2012; Buncic 
and Melecky, 2013). Generally, in economic boom volume of NPLs declines due to better financial condition of households and firms. On contrary, during economic downturn volume of bad loans increases and economic agents have problems to pay off their debts. In the case of interest rate, there is a prevalence of the theoretically assumed effect on the NPLR (84 positive values). This finding suggests that an increase in IR increases NPLR (e.g. Podpiera, 2006; Festić and Bekő, 2008; Buncic and Melecky, 2013). The debt service costs of loans with variable rates are especially sensitive to an increase in interest rates. Higher interest rate increases the debt burden via the rising interest payments, thus economic agents might become insolvent. The economic theory postulates that rising unemployment reduces households' revenues and indicates a future decline in the demand of goods and services for companies. Therefore, rising UNP has adverse effects on credit risk (e.g. Njoroge and Kamau, 2010 or Nkusu, 2011) as is supported by the results in Table 1.

Table 1 | Vote Counting Results

\begin{tabular}{|l|c|c|c|c|c|}
\hline Number of models & REG & IR & INFL & ER & UNP \\
\hline Positive coefficient & 11 & 84 & 35 & 38 & 58 \\
\hline Negative coefficient & 97 & 11 & 21 & 33 & 8 \\
\hline Not reported & 10 & 5 & 10 & 11 & 17 \\
\hline Not included & 28 & 46 & 80 & 64 & 63 \\
\hline Total & $\mathbf{1 4 6}$ & $\mathbf{1 4 6}$ & $\mathbf{1 4 6}$ & $\mathbf{1 4 6}$ & $\mathbf{1 4 6}$ \\
\hline
\end{tabular}

Source: Authors' calculations.

In the case of the ER, there is almost the same number of models with positive coefficients (38) as with negative ones (33). The effect of ER on NPLR is mixed because of two contrary effects - the balance sheet effect and the income effect which are usually not captured in the model specifications in the surveyed studies. Balance-sheet effect postulates that value of loans denominated in foreign currencies (FX) is influenced by the changes in nominal exchange rate. The rise in nominal exchange rate increases the debt burden of unhedged FX loans via higher loan payments. When domestic currency depreciates the debt burden and volume of NPLs increases. Thus the positive relationship between nominal exchange rate and NPLR is assumed in the case of balance-sheet effect. This effect was empirically confirmed e.g. in the case of three central European countries (Hungary, Poland and Slovakia) with high rates of indebtedness in FX (Festić and Bekö, 2008) or in the case of Hong Kong (Shu, 2002). The real appreciation of domestic currency might limit potential of economic growth (through the reduction of profit margins, especially in the export-oriented industries), and might lead to the economic downturn with the direct adverse effect on volume of NPLs (Kaminsky and Reinhart, 1999). Conversely, real depreciation has positive effect on terms of trade and international competitiveness, and therefore, helps to decrease indebtedness of corporate sector. The effect of change in real exchange rate on NPLs is called income 
effect. Total effect of depreciation of domestic currency on NPLs depends on whether the positive impact of higher competitiveness outweighs the negative impact on asset quality (i.e. on unhedged FX exposures).

The economic postulates about the effects of inflation on NPLR are not uniformed as well. For instance, Festić and Romih (2008) postulate that rising INFL makes the macro-economic outlook for the future less transparent. As Fofack (2005) claims, unanticipated rise in INFL may have an adverse effect on performance of banking sector concerning recovery of loans to private operators and investors. Shu (2002) or Gerlach et al. (2005) suggest the opposite relation, i.e. an increase in INFL causes a decline of NPLR due to the erosion of real value of debts and a decrease in real interest rate. Moreover, Shu (2002) points out that inflation tends to be positively correlated with economic growth, which implies smaller amount of defaults and acceleration in lending. Babihuga (2007) discusses ambiguous relationship between INFL and NPLs, while the effect of rising INFL depends on whether it is anticipated and/or whether it coincides with general economic instability. The results presented in Table 1 imply that an adverse effect of INFL on NPLR slightly dominates (35 positive values) compared to the number of coefficients capturing a positive impact (21 negative values).

Table 2 | Meta-Statistics

\begin{tabular}{|l|c|c|c|c|c|}
\hline & REG & IR & INFL & ER & UNP \\
\hline Max. & 1.11 & 2.44 & 1.83 & 1.06 & 1.83 \\
\hline Min. & -8.88 & -0.58 & -0.82 & -4.42 & -0.53 \\
\hline Arithmetic average & -0.96 & 0.24 & 0.26 & -0.02 & 0.45 \\
\hline Median & -0.22 & 0.13 & 0.06 & 0.01 & 0.28 \\
\hline Weighted average (1/SE) & -0.13 & 0.11 & 0.01 & -0.01 & 0.22 \\
\hline Weighted average (NY) & -0.54 & 0.13 & 0.06 & -0.01 & 0.19 \\
\hline Weighted average (NO) & -0.74 & 0.24 & 0.05 & -0.02 & 0.41 \\
\hline
\end{tabular}

Note: The tables containing published coefficients and calculated weighted coefficients for individual models are available upon request.

Source: Authors' calculations.

Table 2 summarizes descriptive statistics of the overall effects of selected drivers obtained from the models (maximum, minimum, arithmetic average, median and weighted averages of published parameters). The weights of the parameters, which represent precision of estimation, are calculated as an inverse to their standard errors. Therefore, more precise estimates (with small SE) gain higher weights. The last two rows provide alternatively calculated weighted averages, which use the number of years (NY) and the number of observations (NO) included in the models as the weights (see e.g. Knell and Stix, 2005). However, it needs to be pointed out that these alternative approaches to setting 
weights do not directly capture the precision of the estimates (as it is in the case of $1 / \mathrm{SE}$ ). ${ }^{2}$ Arithmetic averages are of higher values compared to the WA or median values. Arithmetic averages are more sensitive to outliers in the data sample and assign higher weights to less significant estimates or estimates based on a smaller data sample than medians and WA. Median values are closer to the averages weighted by $1 / \mathrm{SE}$ than to alternative WA, especially in the case of IR and ER. Both alternative ways of weighing parameters produce in most cases higher values of averages compared to the averages weighted by $1 / \mathrm{SE}$. In the case of exchange rate, computed values of all averages are very small. This finding might be caused by the presence of the aforementioned two contrary effects of the ER on NPLR which are mostly not separately specified in the studies.

\section{Meta-Regression Analysis}

This section focuses on the identification of study-specific factors, which may affect results obtained from the surveyed studies. The estimation method preferred in this analysis is the weighted least squares. Typical meta-regression is thus given as in Equation 1

$$
\hat{\beta}_{i, j}=\mu+D_{j} \theta+u_{i, j} .
$$

where $\mu$ is a constant, $\hat{\beta}_{i, j}$ is the weighted coefficient estimate corresponding to variable $i$ in model $j$ and $D_{j}$ is a matrix containing variables reflecting various characteristics of the model and $u_{i, j}$ is an error term which may have a different distribution for each of the analysed models, see e.g. Cuaresma et al. (2011). The matrix $D_{j}$ includes both a continuous and dummy variable.

The meta-regression model could be estimated using OLS method but such an estimation method does not take into account the precision of the individual estimates of parameters. An alternative approach to OLS is to employ the WLS estimation method by taking into account the precision of each parameter estimate, which is measured by the inverse of their SE (see Knell and Stix, 2005). The dummy variables are used in the meta-regressions (except the one for inflation) to avoid identification problems due to the existence of extreme outliers.

As a control variable we include variables describing data sets (e.g. the frequency and level of data, and the number of observations of individual studies). Further, control variables that identify a dynamic form of model specification and the method of estimation are employed. Also variables describing the number of countries included in a study, and whether these countries are European are taken into account. The last characteristics used as control variables are those identifying whether the part of the data set covers the crisis period and whether studies are published in a journal with an IF. The control variables were chosen based on their availability in all studies selected for the meta-analysis and also experiences of other authors (Cuaresma et al., 2011 or Havránek and Sedlař́ková, 2014). A detailed description of control variables is provided in the Table 3.

2 For instance, in a panel data study with a large number of observations even estimated coefficients with low significance are assigned a high weight. 
Table 3 | Definitions of the Control Variables Used in Meta-Regressions

\begin{tabular}{|c|c|c|}
\hline Variable & Abr. & Definition \\
\hline Average year & AY & $\begin{array}{l}\text { CV: Average year of data set (the year } 2000 \text { was used as a base) } \\
\text { of an individual model }\end{array}$ \\
\hline Number of years & NY & CV: Number of years included in the data set of an individual model \\
\hline $\begin{array}{l}\text { Number } \\
\text { of observations }\end{array}$ & NO & $\begin{array}{l}\text { CV: Natural logarithm of the number of observations included } \\
\text { in an individual model }\end{array}$ \\
\hline Frequency of data & FRQ & BD: 1 if the frequency of data is quarterly, 0 otherwise \\
\hline Level of data & $\mathrm{BL}$ & BD: 1 if bank-level data are used, 0 otherwise \\
\hline Multiple countries & MC & $\begin{array}{l}\text { BD: } 1 \text { if the number of countries included in model is higher than } \\
\text { one, } 0 \text { otherwise }\end{array}$ \\
\hline European countries & $\mathrm{EC}$ & $\begin{array}{l}\text { BD: } 1 \text { if at least one country included in model is European, } \\
0 \text { otherwise }{ }^{4}\end{array}$ \\
\hline $\begin{array}{l}\text { Dynamic } \\
\text { specification }\end{array}$ & DYN & BD: 1 if model specification is dynamic, 0 otherwise \\
\hline Impact factor & IF & $\begin{array}{l}\text { BD: } 1 \text { if the study is published in a journal with an IF from the WOS, } \\
0 \text { otherwise }\end{array}$ \\
\hline Estimation method & OLS & BD: 1 if method of estimation is OLS, 0 otherwise \\
\hline Crisis included & CRIS & $\begin{array}{l}\text { BD: } 1 \text { if crisis years (from } 2008 \text { to present) are included in the data } \\
\text { set, } 0 \text { otherwise }\end{array}$ \\
\hline
\end{tabular}

Note: CV - continuous variable, BD - binary dummy.

Source: Authors.

\section{Discussion of Empirical Results}

Within the meta-regression analysis, we employed WLS to identify the effects and significance of control variables for the five macroeconomic determinants of NPLR. The preferred method of setting weights is 1/SE. However, we also have checked the significance of control variables with the use of two alternative weighting approaches based on the NY included in the data sample of each model and the NO included in the models. In general, both increased NY and increased NO should lead to more precise estimates so the coefficients estimated by the models with large number of observations/ years are getting higher weights. Most effects of control variables that are significant under 1/SE weights are also significant under NO and/or NY weights.

3 The binary variable MC is designed to differ individual effects of country-specific studies from effects of cross-country studies based on international experience.

4 The binary variable EC is designed to investigate whether the studies ' focus on European countries has significant effect on the estimation results because more than half of selected studies include European countries. 
The results are reported in the following pattern. Firstly, the scatter plots of weighted coefficients and respective weights (1/SE) are presented. Secondly, the effects of control variables estimated in meta-regressions are discussed. Due to the presence of autocorrelation and/or heteroscedasticity in the models, we have used a HAC matrix during the estimation to get correct (unbiased) values of the SE of the estimated coefficients of control variables. Finally, we have designed sub-samples based on meta-regressions results and have calculated their weighted averages. Sub-samples analysis focuses on subgroups created based on the control variables that explain the differences in effects across the models that are found to be statistically significant in meta-regression analysis.

\section{Real economic growth}

Figure 1 captures weighted coefficients of REG in NPLR regressions (horizontal axis) and their weights (vertical axis). There is also a histogram displayed on each axis. The vertical lines highlight the values of weighted coefficients with the highest assigned weights (the most precise ones). The majority of weighted coefficients reaches negative values while weighted coefficients with the highest weights are of minor negative size. There is one outlier with a high negative value but rather low weight. This extreme value of weighted coefficient comes from the study Festić and Romih (2008) and its OLS estimation for Slovenia in the period 1995-2006. Positive values are reported mostly in the journals without impact factor (IF, 10 out of 11).

Figure 1 | Weighted Coefficients of REG and Their Weights

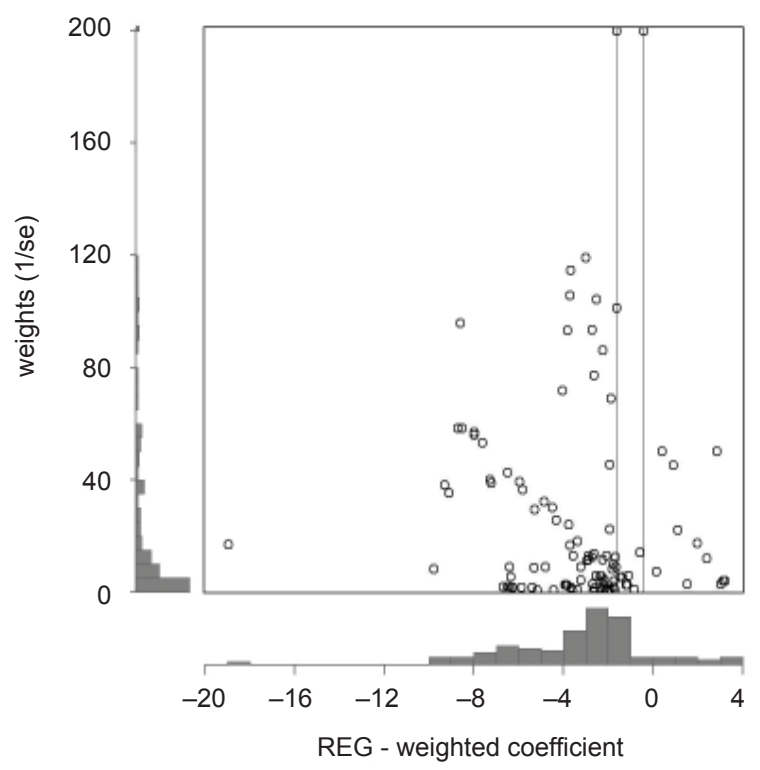

Source: Authors' calculations. 
Table 4 provides the results of meta-regression for REG as a determinant of NPLR. The first column contains parameters labels, the second column shows the estimated coefficients and their significance and the last column captures respective standard errors. The estimation results suggest that statistically significant differences among effects of REG on NPLR are caused by a different frequency of data, the number of observations included in the models, the number of years (i.e. time span of data), and finally, if the method of estimation is OLS or other. For instance, if the number of observations captured by the data increases by one, the weighted effect of the REG on NPLR decreases by -0.98 at $1 \%$ significance level. Another example is $\beta_{\text {OLS }}$ which says that if the estimation method employed in the model is the OLS, then the weighted effect of REG on NPLR should be higher compared to the one gained by an alternative method of estimation.

Table 4 | Meta-Regression Results for REG

\begin{tabular}{|l|c|c|}
\hline Parameter & E. C. & SE \\
\hline $\boldsymbol{a}$ & 3.26 & 1.20 \\
\hline $\boldsymbol{\beta}_{A Y}$ & -0.17 & 0.21 \\
\hline $\boldsymbol{\beta}_{B L}$ & -0.48 & 1.00 \\
\hline $\boldsymbol{\beta}_{C R I S}$ & 1.91 & 1.52 \\
\hline $\boldsymbol{\beta}_{\text {DYN }}$ & -0.07 & 0.90 \\
\hline $\boldsymbol{\beta}_{E C}$ & -0.09 & 0.97 \\
\hline $\boldsymbol{\beta}_{F R Q}$ & $-1.92^{* *}$ & 0.94 \\
\hline $\boldsymbol{\beta}_{\text {IF }}$ & -0.17 & 0.88 \\
\hline $\boldsymbol{\beta}_{M C}$ & 0.50 & 0.87 \\
\hline $\boldsymbol{\beta}_{N O}$ & $-0.98^{* * *}$ & 0.36 \\
\hline $\boldsymbol{\beta}_{N Y}$ & $-0.17^{*}$ & 0.09 \\
\hline $\boldsymbol{\beta}_{\text {OLS }}$ & $1.12^{* *}$ & 0.52 \\
\hline $\boldsymbol{\beta}_{\text {Dummy }}$ & $-16.51^{* * *}$ & 0.90 \\
\hline R-squared & 0.46 & \\
\hline Prob (F-statistic) & 0.00 & \\
\hline Schwarz c. & 108 & \\
\hline Number of observations & & \\
\hline
\end{tabular}

Note: ${ }^{*},{ }^{* *},{ }^{* *}$ denotes statistical significance at $10 \%, 5 \%$ and $1 \%$ level, respectively.

Source: Authors' calculations. 
In the previous step we identified four statistically significant factors (control variables) that cause differences in the estimated effects of REG on NPLR among models. Table 5 reports the WA of sub-samples created based on the results of meta-regression analysis. If a variable is found to be significant in meta-regression at least at $10 \%$ level, the subgroup for the variable's effect is created and the WA effect for this sub-group is calculated. For instance, the quarterly frequency of the data is significant based on the results presented in Table 4 so the effects are divided into sub-groups, which contain models only with annual data, quarterly data and monthly data. Bivariate variables as e.g. OLS, are divided into two sub-groups and for the variables with a wide range of possible values, as e.g. $\mathrm{NO}$, we created interval sub-groups. For instance, in the case of NO, sub-sample analysis, it confirms the idea suggested by meta-regression analysis that with the increasing NO the estimated effect of REG on NPLR decreases. Models with less than 100 observations find on the average significantly lower effects $(-0.05)$ than models with 100 and more observations ( -0.14 for $100 \leq \mathrm{NO} \leq 300$ sub-group and -0.20 for $\mathrm{NO}>300$ sub-group). WA of OLS sub-groups are in line with meta-regression results for REG, i.e. models with the applied OLS method of estimation produce higher estimated coefficients (WA of OLS YES sub-group reaches smaller negative values than OLS_NO sub-group).

Table 5 | Weighted Averages of Sub-Samples for Significant Control Variables of REG

\begin{tabular}{|l|c|}
\hline Sub-sample & WA \\
\hline FRQ_A & -0.20 \\
\hline FRQ_Q & -0.09 \\
\hline FRQ_M & -0.14 \\
\hline NY $<\mathbf{1 0}$ & -0.21 \\
\hline NY $\geq \mathbf{1 0}$ & -0.09 \\
\hline OLS_YES & -0.09 \\
\hline OLS_NO & -0.19 \\
\hline NO $<\mathbf{1 0 0}$ & -0.05 \\
\hline 100 $\leq$ NO $\leq \mathbf{3 0 0}$ & -0.14 \\
\hline NO $>\mathbf{3 0 0}$ & -0.21 \\
\hline
\end{tabular}

Source: Authors' calculations.

\section{Interest rate}

The majority of weighted coefficients of IR are positive and the weighted coefficients with the highest weights are of minor positive size (see Figure 2). There is one outlier with a high positive value and of medium weight. This weighted coefficient was calculated based on the results of the study Festić and Bekö (2008) and its estimation for Poland in the time period 1995-2007. Negative values are reported mostly in the journals without an IF (9 out of 11). 


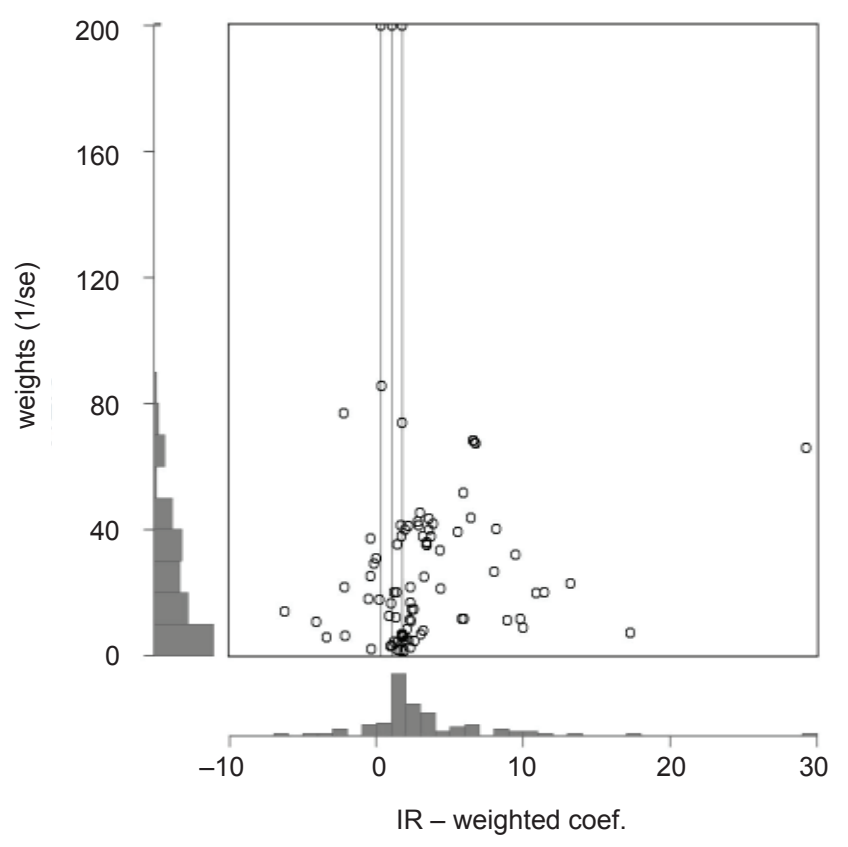

Source: Authors' calculations.

Table 6 provides the results of meta-regression for IR. The estimation results suggest that statistically significant differences among effects of IR in NPLR regressions are caused by data characteristics, specifically, the average year of the data sample in the model and data frequency. For instance, if data frequency is quarterly then the weighted effect of interest rate on NPLR will rise significantly $\left(\operatorname{see} \beta_{F R Q}\right)$.

Table 7 reports the WA of sub-samples that are created based on the regression results. Quarterly frequency of the data is found to be significant so the effects are divided into subgroups which contain models with annual data, quarterly data and monthly data. In the case of the control variable average year, three sub-groups are created. The results are partly in line with respective meta-regression because models with an average year of the data sample until 1999 find on average lower effects of IR on NPLR compared to the models with an average year from 2000 to 2005 (the WA 0.12 vs. 0.08). However, if AY rises above 2006 then the respective WA increases again. 
Table 6 | Meta-Regression Results for IR

\begin{tabular}{|l|c|c|}
\hline Parameter & E. C. & SE \\
\hline $\boldsymbol{a}$ & -1.01 & 3.63 \\
\hline $\boldsymbol{\beta}_{A Y}$ & $-0.43^{* * *}$ & 0.13 \\
\hline $\boldsymbol{\beta}_{B L}$ & 1.04 & 1.25 \\
\hline $\boldsymbol{\beta}_{C R I S}$ & -1.63 & 1.24 \\
\hline $\boldsymbol{\beta}_{\text {DYN }}$ & 0.64 & 1.06 \\
\hline $\boldsymbol{\beta}_{E C}$ & -0.46 & 1.08 \\
\hline $\boldsymbol{\beta}_{F R Q}$ & $4.43^{* *}$ & 1.90 \\
\hline $\boldsymbol{\beta}_{\text {IF }}$ & -1.28 & 1.18 \\
\hline $\boldsymbol{\beta}_{M C}$ & 1.47 & 1.17 \\
\hline $\boldsymbol{\beta}_{\text {No }}$ & 0.98 & 0.61 \\
\hline $\boldsymbol{\beta}_{\text {NY }}$ & -0.13 & 0.11 \\
\hline $\boldsymbol{\beta}_{\text {OLS }}$ & -0.87 & 0.88 \\
\hline $\boldsymbol{\beta}_{\text {Dummy }}$ & $21.26^{* * *}$ & 2.09 \\
\hline R-squared & 0.62 & \\
\hline Prob(F-statistic) & 0.00 & \\
\hline Schwarz C. & 5.48 & \\
\hline Number of observations & 95 & \\
\hline
\end{tabular}

Note: ${ }^{* * *},{ }^{* * *}$ denotes statistical significance at $10 \%, 5 \%$ and $1 \%$ level, respectively.

Source: Authors' calculations.

Table 7 | Weighted Averages of Sub-Samples for Significant Control Variables of IR

\begin{tabular}{|l|l|}
\hline Sub-samples & WA \\
\hline FRQ_A & 0.12 \\
\hline FRQ_Q & 0.12 \\
\hline FRQ_M & 0.00 \\
\hline AY until 1999 & 0.13 \\
\hline AY from 2000 to 2005 & 0.09 \\
\hline AY from 2006 & 0.23 \\
\hline
\end{tabular}

Source: Authors' calculations. 


\section{Inflation}

In the case of INFL, the values of weighted coefficients vary significantly. The weighted coefficient with the highest weight (marked with the vertical line) is of rather small negative size. There is a significant amount of coefficients with high weights with values close to zero. About $63 \%$ of coefficients are positive. There are both high positive and high negative coefficients in the group. Most of the negative values are reported in the journals without an IF (18 out of 21).

Figure 3 | Weighted Coefficients of INFL and Their Weights

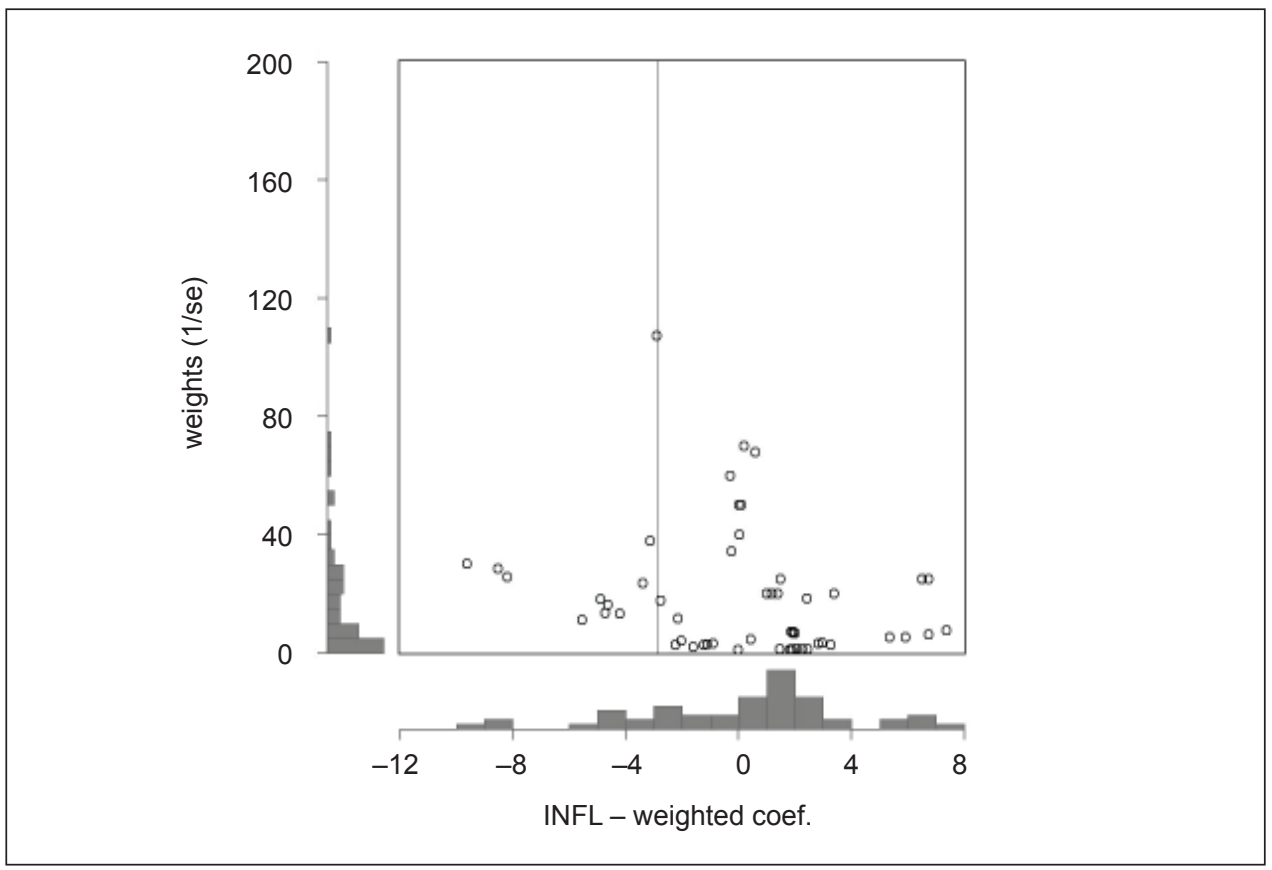

Source: Authors' calculations.

The estimation results suggest that there are quite a lot of statistically significant factors that cause differences among the effects of INFL in NPLR regressions (see Table 8). Those differences are caused by data characteristics, more specifically, the average year of the data covered by the model, data frequency, the number of years and the number of observations included in the model, the inclusion of European countries in the data sample and the scope on bank-level data. Dynamic specification of the model plays the role as well. Finally, the weighted effects differ across models according to the fact whether they are published in a journal with an IF or other types of journals/working papers. The weighted coefficients of inflation effect on NPLR published in a journal with IF are significantly higher than the weighted coefficients in other types of studies (see $\left.\beta_{I F}\right)$. 
Table 8 | Meta-Regression Results for INFL

\begin{tabular}{|l|c|c|}
\hline Parameter & E.C. & SE \\
\hline $\boldsymbol{a}$ & $-7.48^{* * *}$ & 2.31 \\
\hline $\boldsymbol{\beta}_{A Y}$ & $0.97^{* * *}$ & 0.24 \\
\hline $\boldsymbol{\beta}_{B L}$ & $-8.06^{* * *}$ & 1.91 \\
\hline $\boldsymbol{\beta}_{C R I S}$ & 1.09 & 1.89 \\
\hline $\boldsymbol{\beta}_{D Y N}$ & $3.73^{* * *}$ & 1.21 \\
\hline $\boldsymbol{\beta}_{E C}$ & $-3.96^{*}$ & 2.15 \\
\hline $\boldsymbol{\beta}_{F R Q}$ & $-4.12^{* * *}$ & 0.96 \\
\hline $\boldsymbol{\beta}_{I F}$ & $3.96^{* * *}$ & 1.39 \\
\hline $\boldsymbol{\beta}_{M C}$ & -1.88 & 1.55 \\
\hline $\boldsymbol{\beta}_{N O}$ & $2.50^{* * *}$ & 0.53 \\
\hline $\boldsymbol{\beta}_{N Y}$ & $-0.57^{* * *}$ & 0.10 \\
\hline $\boldsymbol{\beta}_{\text {OLS }}$ & -0.47 & 0.87 \\
\hline R-squared & 0.69 & \\
\hline Prob(F-statistic) & 0.00 & \\
\hline Schwarz C. & 5.12 & \\
\hline Number of observations & 56 & \\
\hline & & \\
\hline
\end{tabular}

Note: ${ }^{* * *},{ }^{* * *}$ denotes statistical significance at $10 \%, 5 \%$ and $1 \%$ level, respectively. Source: Authors' calculations.

Table 9 reports the WA of sub-samples created based on the regression results. The sub-groups are created and the WA effects are calculated for all variables that are found to be statistically significant in meta-regression for INFL at least at a $10 \%$ significance level. For instance, models with a number of observations smaller than 100 tend to produce on the average minor positive estimates of coefficients. Models with a number of observations from 100 to 300 (mostly smaller panels) find on the average a negative weighted effect. However, in the models with a number of observations over 300 (larger panels) we found relatively a large positive value of WA. Subsample analysis confirms previous finding implied by meta-regression analysis that journals with an IF report larger coefficients (WA 0.04) compared to other types of studies. 
Table 9 | Weighted Averages of Sub-Samples for Significant Control Variables of INFL

\begin{tabular}{|l|c|}
\hline Sub-samples & WA \\
\hline AY until 1999 & -0.31 \\
\hline AY from 2000 to 2005 & 0.03 \\
\hline AY from 2006 & 0.23 \\
\hline BL_YES & 0.03 \\
\hline BL_NO & 0.01 \\
\hline DYN_YES & -0.02 \\
\hline DYN_NO & 0.06 \\
\hline EC_YES & 0.05 \\
\hline EC_NO & -0.06 \\
\hline FRQ_A & 0.04 \\
\hline FRQ_Q & -0.03 \\
\hline FRQ_M & -0.14 \\
\hline NO < 100 & 0.02 \\
\hline 100 $\leq$ NO $\leq \mathbf{3 0 0}$ & -0.01 \\
\hline NO > 300 & 0.21 \\
\hline NY < 10 & 0.06 \\
\hline NY $\mathbf{1 0}$ & -0.03 \\
\hline IF_YES & 0.04 \\
\hline IF_NO & 0.01 \\
\hline
\end{tabular}

Source: Authors' calculations.

\section{Exchange rate}

The weighted coefficients of ER are almost evenly distributed between positive and negative values (see Figure 4) and coefficients with high weights are rather smaller with one exception (the extremely negative value of weighted coefficient of a medium weight). This value comes from the panel study Babihuga (2007), which includes data of 96 countries and covers time period from 1998 to 2004. Furthermore, there are two weighted coefficients of high negative value but rather lower weight. These values were obtained based on the estimation results of studies Festić and Romih (2008) and Festić and Bekő (2008), and are associated with the OLS estimations for Slovenia in the periods 19952006 and 1995-2007, respectively. The weighted coefficients with the highest weights are in the three cases positive but in the one case negative. Negative coefficients are more often reported in journals without an IF than in the journals with an IF. 


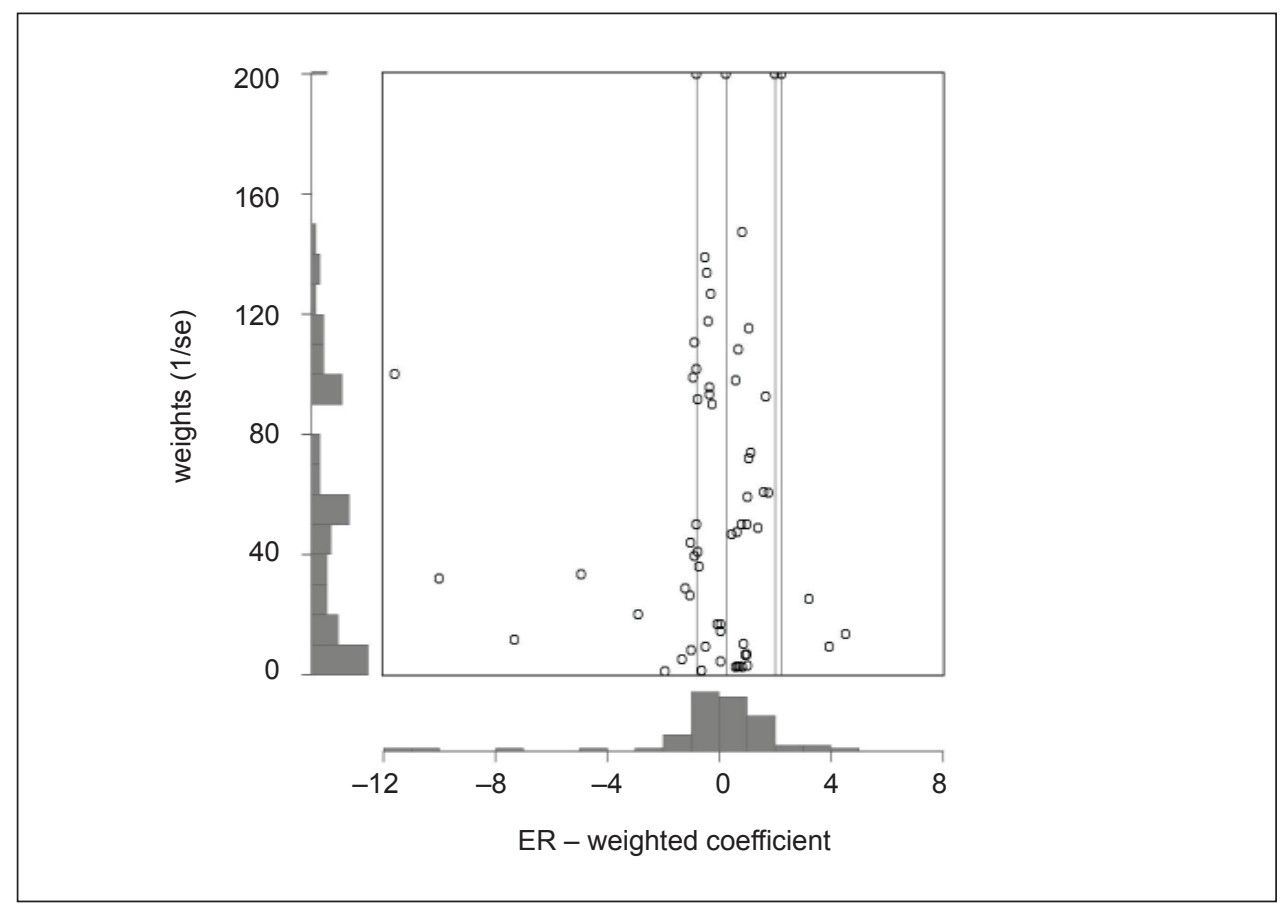

Source: Authors' calculations.

Based on the estimation results the differences among the effects of ER in NPLR regressions come from data characteristic, specifically, data frequency and inclusion of European countries in the data sample (see Table 10). Another factor that significantly influences estimated coefficients whether the method of estimation, i.e. if a model uses the OLS method or other. As in the case of inflation, there are significant differences across models that are published in the journal with an IF and other types of journals/ working papers. The weighted coefficients of ER effect on NPLR in the journals with an IF are significantly higher compared to the weighted coefficients in other types of studies $\left(\right.$ see $\left.\beta_{I F}\right)$.

Based on meta-regression results for exchange rate, we have created sub-samples for four statistically significant variables which are reported in Table 11. For instance, models including data from European countries tend to produce on the average minor negative coefficient estimates, whereas models that are not focussed on European countries find on the average minor positive effect of ER on NPLR. Sub-sample analysis confirms previous finding that journals with an IF report larger and on the average positive coefficients (WA 0.02) compared to the other types of studies (negative average effect -0.02). 
Table 10 | Meta-Regression Results for ER

\begin{tabular}{|l|c|c|}
\hline Parameter & E.C. & SE \\
\hline $\boldsymbol{a}$ & 3.46 & 3.36 \\
\hline $\boldsymbol{\beta}_{A Y}$ & 0.37 & 0.26 \\
\hline $\boldsymbol{\beta}_{B L}$ & -0.85 & 1.61 \\
\hline $\boldsymbol{\beta}_{C R I S}$ & -3.41 & 2.43 \\
\hline $\boldsymbol{\beta}_{\text {DYN }}$ & 1.55 & 1.02 \\
\hline $\boldsymbol{\beta}_{E C}$ & $-3.31^{* * *}$ & 1.10 \\
\hline $\boldsymbol{\beta}_{F R Q}$ & $3.37^{* * *}$ & 1.20 \\
\hline $\boldsymbol{\beta}_{I F}$ & $2.40^{* *}$ & 0.94 \\
\hline $\boldsymbol{\beta}_{M C}$ & 2.49 & 1.49 \\
\hline $\boldsymbol{\beta}_{N O}$ & -0.70 & 0.69 \\
\hline $\boldsymbol{\beta}_{N Y}$ & 0.06 & 0.13 \\
\hline $\boldsymbol{\beta}_{\text {oLS }}$ & $-1.36^{* *}$ & 0.64 \\
\hline $\boldsymbol{\beta}_{\text {Dummy }}$ & $-24.60^{* * *}$ & 1.41 \\
\hline R-squared & 0.86 & \\
\hline Prob(F-statistic) & 0.00 & \\
\hline Schwarz C. & 5.26 & \\
\hline Number of observations & 71 & \\
\hline
\end{tabular}

Note: ${ }^{* * *},{ }^{* * *}$ denotes statistical significance at $10 \%, 5 \%$ and $1 \%$ level, respectively. Source: Authors' calculations.

Table 11 | Weighted Averages of Sub-Samples for Significant Control Variables of ER

\begin{tabular}{|l|c|}
\hline Sub-sample & WA \\
\hline EC_YES & -0.01 \\
\hline EC_NO & 0.01 \\
\hline IF_YES & 0.02 \\
\hline IF_NO & -0.02 \\
\hline FRQ_A & -0.02 \\
\hline FRQ_Q & 0.04 \\
\hline FRQ_M & -0.54 \\
\hline OLS_YES & -0.02 \\
\hline OLS_NO & 0.01 \\
\hline
\end{tabular}

Source: Authors' calculations. 


\section{Unemployment}

In the case of unemployment, the weighted coefficients with the highest weights are close to zero and the majority of the coefficients takes rather small positive values (see Figure 5). There is one outlier with high positive value calculated based on the results of working paper of Nkusu (2011) which represents the advanced countries' panel study from period 19982009. This extreme value of weighted coefficient is associated with very small estimated standard error and high value of its weight.

Figure 5 | Weighted Coefficients of UNP and Their Weights

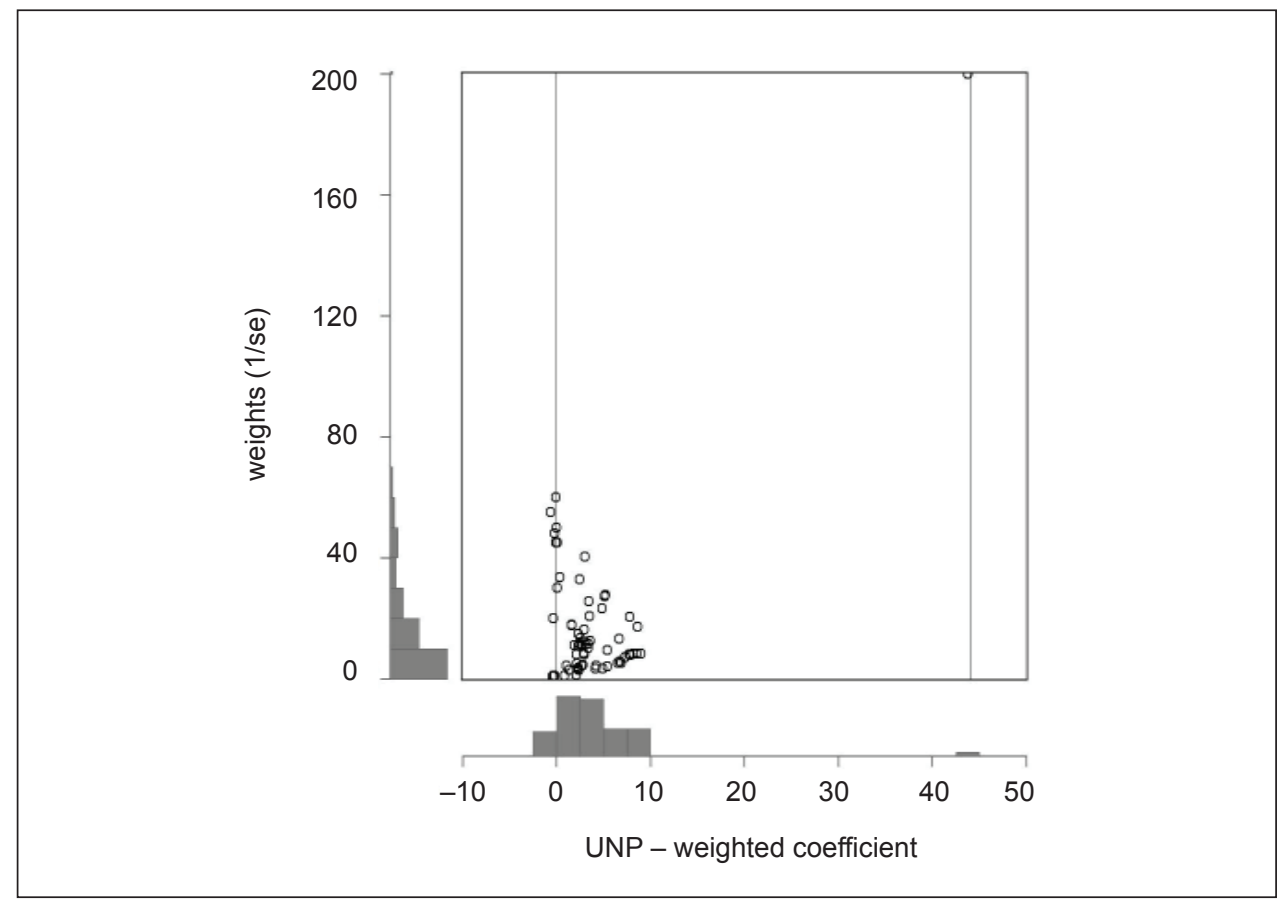

Source: Authors' calculations.

The estimation results suggest that differences among the effects of unemployment on NPLR come from two characteristics (see Table 12). These are the average year of the data sample and the fact if the model focuses on one or multiple countries. Based on the meta-regression results, for instance, models that include a higher share of more recent data (have a higher average year of data sample) report higher weighted coefficients. 
Table 12 | Meta-Regression Results for UNP

\begin{tabular}{|l|c|c|}
\hline \multicolumn{1}{|c|}{ Parameter } & E.C. & SE \\
\hline $\boldsymbol{\alpha}$ & 1.21 & 5.12 \\
\hline $\boldsymbol{\beta}_{A Y}$ & $0.29^{*}$ & 0.17 \\
\hline $\boldsymbol{\beta}_{B L}$ & 1.65 & 2.68 \\
\hline $\boldsymbol{\beta}_{C R I S}$ & 0.66 & 1.11 \\
\hline $\boldsymbol{\beta}_{D Y N}$ & -1.83 & 1.30 \\
\hline $\boldsymbol{\beta}_{E C}$ & -2.54 & 1.52 \\
\hline $\boldsymbol{\beta}_{F R Q}$ & 0.75 & 1.73 \\
\hline $\boldsymbol{\beta}_{I F}$ & 0.60 & 1.60 \\
\hline $\boldsymbol{\beta}_{M C}$ & $2.40^{*}$ & 1.20 \\
\hline $\boldsymbol{\beta}_{N O}$ & 0.18 & 0.79 \\
\hline $\boldsymbol{\beta}_{N Y}$ & -0.10 & 0.19 \\
\hline $\boldsymbol{\beta}_{\text {OLS }}$ & 1.66 & 1.04 \\
\hline $\boldsymbol{\beta}_{\text {Dummy }}$ & $41.22^{* * *}$ & 0.97 \\
\hline R-squared & 0.92 & \\
\hline Prob(F-statistic) & 0.00 & \\
\hline Schwarz C. & 4.65 & \\
\hline Number of observations & 66 & \\
\hline
\end{tabular}

Note: ${ }^{* *},{ }^{* * *}$ denotes statistical significance at $10 \%, 5 \%$ and $1 \%$ level, respectively.

Source: Authors' calculations.

Table 13 | Weighted Averages of Sub-Samples for Significant Control Variables of UNP

\begin{tabular}{|l|l|}
\hline Sub-samples & WA \\
\hline AY until 2000 & 0.44 \\
\hline AY from 2000 to 2005 & 0.12 \\
\hline AY from 2006 & 0.63 \\
\hline MC_YES & 0.18 \\
\hline MC_NO & 0.46 \\
\hline
\end{tabular}

Source: Authors' calculations. 
Sub-sample analysis reveals that models with an average year of the data sample between 2000 and 2005 find on the average smaller effects than studies with AY until 2000 and AY higher than 2006 (see Table 13). Further, models focused on multiple countries are not producing higher coefficients compared to the studies focused on an individual country as is suggested by meta-regression analysis but on the contrary lower coefficients.

\section{Conclusion}

This article focuses on a quantitative survey of growing literature on credit risk determinants that emerged especially in the last decade. To our knowledge, this article is the first one that provides more general information on the effects of macroeconomic credit risk drivers with the help of meta-analytic techniques. We analysed only those studies which use NPLR as an indicator of credit risk. We investigated the effects of the five most frequently used macroeconomic determinants of non-performing loans ratio presented in the relevant literature: real economic growth, interest rate, inflation, unemployment and exchange rate. We identified 37 studies with 146 models and almost 400 parameter estimates of the five selected drivers. The average effects of selected macroeconomic credit risk drivers weighted by an inverse of the SE of individual effects are significantly different from the arithmetic averages. Both alternative ways of setting parameters weights (by the number of years and number of observations) mostly confirm significant effects of control variables identified by the preferred way of setting weights. However, alternative weightings produce in most cases higher values of calculated weighted averages compared to the averages weighted by an inverse of SE.

The meta-regression analysis identified significant differences among studies. The number of statistically significant factors (at least at the 10\% level) that cause the differences varies across selected macroeconomic determinants with the highest number of significant factors identified in the case of inflation ( 8 of 11 control variables). The differences in the weighted effects of determinants on NPLR are most often due to data specification, specifically, data frequency ( 4 of 5 determinants) and the average year of the data sample used in the model ( 3 of 5 determinants). We identified the following control variables to be two times statistically significant: the inclusion of European countries, the OLS estimation method, publication in a journal with an IF, the number of years and the number of observations in the data sample.

Further, statistically significant control variables were used to create sub-groups from published effects and for each sub-group the averages weighted by an inverse of SE were calculated. The meta-regression results are often confirmed by the sub-sample analysis. For instance, in the case of real economic growth, the sub-sample analysis for the number of observations confirms the idea suggested by meta-regression analysis that with the increasing number of observations the estimated effect of REG on NPLR decreases. Another example might be inflation`s sub-sample analysis which confirms previous finding implied by meta-regression analysis, that journals with an IF report larger coefficients 
compared to other types of studies. The weighted effect of inflation based on all models included in the analysis seems to be almost zero. However, a closer look at sub-groups for an average year reveals that studies containing models with older data (up to average year 1999) tend to publish on the average the negative effects of inflation on NPLR whereas more recent studies publish on the average positive values (especially those with average year 2006 or later).

Both meta-regression analysis and following sub-samples analysis reveal significant factors, which cause differences in estimated coefficients across empirical literature. Moreover, calculated weighted averages could be used to calibrate future models, e.g. to set priors in Bayesian based models (e.g. Melecký et al., 2015) or to compare ones' results with a broader set of studies.

\section{References}

Ahmad, F., Bashir, T. (2013). Explanatory Power of Macroeconomic Variables as Determinants of Non-Performing Loans: Evidence from Pakistan. World Applied Sciences Journal, 22(2), 243-255, https://doi.org/10.5829/idosi.wasj.2013.22.02.1863

Alhassan, A. L., Kyereboah-Coleman, A., Andoh, Ch. (2014). Asset Quality in a Crisis Period: An Empirical Examination of Ghanaian Banks. Review of Development Finance, 4(1), 50-62, https://doi.org/10.1016/j.rdf.2014.03.001

Babihuga, R. (2007). Macroeconomic and Financial Soundness Indicators: An Empirical Investigation. International Monetary Fund. Working Paper No. 07/115, https://doi. org/10.5089/9781451866797.001

Babouček, I., Jančar, M. (2005). A VAR Analysis of the Effects of Macroeconomic Shocks to the Quality of the Aggregate Loan Portfolio of the Czech Banking Sector. Czech National Bank. Working Paper Series No. 1.

Bofondi, M., Ropele, T. (2011). Macroeconomic Determinants of Bad Loans: Evidence from Italian Banks. Banca D'Italia. Occasional Papers No. 89, https://doi.org/10.2139/ssrn.1849872

Bonfim, D. (2009). Credit Risk Drivers: Evaluating the Contribution of Firm Level Information and of Macroeconomic Dynamics. Journal of Finance and Banking, 33(2), 281-299, https://doi.org/10.1016/j.jbankfin.2008.08.006

Borio, K. (2003). Towards a Macroprudential Framework for Financial Supervision and Regulation? Bank for International Settlements. BIS Working Paper No. 128, https://doi.org/10.2139/ ssrn.841306.

Boss, M., Fenz, G., Pann, J., Puhr, C., Schneider, M., Ubl, E. (2009). Modeling Credit Risk through the Austrian Business Cycle: An Update of the OeNB Model, in Oesterreichische Nationalbank, ed., Financial Stability Report 17. Vienna: Oesterreichische Nationalbank, pp. 85-101.

Buncic, D., Melecky, M. (2013). Macroprudential Stress Testing of Credit Risk: A Practical Approach for Policy Makers. Journal of Financial Stability, 9(3), 347-370, https://doi. org/10.1016/j.jfs.2012.11.003

Castro, V. (2013). Macroeconomic Determinants of the Credit Risk in the Banking System: The Case of the GIPSI. Economic Modelling, 31(C), 672-683, https://doi.org/10.1016/j. econmod.2013.01.027 
Choy, I. W. T. (2014). The Effect of Macroeconomic Shocks on Financial Stability in Macao, in Chan, S. S., ed., Macao Monetary Research Bulletin No. 30. Calçada do Gaio: Monetary Authority of Macao, 91-117.

Cifter, A., Yilmazer, S., Cifter, E. (2009). Analysis of Sectoral Credit Default Cycle Dependency with Wavelet Networks: Evidence from Turkey. Economic Modelling, 26(6), 1382-1388, https://doi.org/10.1016/j.econmod.2009.07.014

Cuaresma, C. J., Fidrmuc, J., Hake, M. (2011). Determinants of Foreign Currency Loans in CESEE Countries: A Meta-Analysis. Focus on European Economic Integration, Q4/11, 69-87.

de Bock, R., Demyanets, A. (2012). Bank Asset Quality in Emerging Markets: Determinants and Spillovers. International Monetary Fund. Working Paper No. 12/71, https://doi. org/10.5089/9781475502237.001

Espinoza, R., Prasad, A. (2010). Nonperforming Loans in the GCC Banking System and Their Macroeconomic Effects. International Monetary Fund. Working Paper No. 10/224, https://doi.org/10.5089/9781455208890.001

Festić, M., Bekő, J. (2008). The Banking Sector and Macroeconomic Performance in Central European Economies. Czech Journal of Economics and Finance, 58(3-4), 131-151.

Festić, M., Romih, D. (2008). Cyclicality of the Banking Sector Performance and Macro Environment in the Czech Republic, Slovakia and Slovenia. Prague Economic Papers, 17(2), 99-117, https://doi.org/10.18267/j.pep.323

Festić, M., Repina, S., Kavkler, A. (2009). The Overheating of Five EU New Member States and Cyclicality of Systemic Risk in the Banking Sector. Journal of Business Economics and Management, 10(2), 219-232, https://doi.org/10.3846/1611-1699.2009.10.219-232

Fofack, H. L. (2005). Nonperforming Loans in Sub - Saharan Africa: Casual Analysis and Macroeconomic Implications. World Bank. Policy Research Working Paper No. 3769, https://doi.org/10.1596/1813-9450-3769

Gerlach, S., Peng, W., Shu, Ch. (2005). Macroeconomic Conditions and Banking Performance in Hong Kong SAR: A Panel Data Study. Bank for International Settlements. BIS Papers No. 22.

Greenidge, K., Grosvenor, T. (2010). Forecasting Non-Performing Loans in Barbados. Business, Finance \& Economics in Emerging Economies, 5(1), 80-108.

Gremi, E. (2013). Macroeconomic Factors That Affect the Quality of Lending in Albania. Research Journal of Finance and Accounting, 4(9), 50-57.

Guy, K., Lowe, S. (2011). Non-Performing Loans and Bank Stability in Barbados. Economic Review, 37(1), 77-99.

Havránek, T., Sedlaříková, J. (2014). A Meta-Analysis of the Income Elasticity of Money Demand. Politická ekonomie, 62(3), 366-382, https://doi.org/10.18267/j.polek.956

Hoggarth, G., Logan, A., Zicchino, L. (2005). Macro Stress Tests of UK Banks. Bank for International Settlements. BIS Paper No. 22.

Jakubík, P., Reininger, T. (2013). Determinants of Nonperforming Loans in Central, Eastern and Southeastern Europe. Focus on the European Economic Integration, Q3/2013, 48-66.

Jiménez, G., Saurina, J. (2006). Credit Cycles, Credit Risk, and Prudential Regulation. International Journal of Central Banking, 2(2), 65-98.

Kasselaki, M., Tagkalakis, A. (2014). Financial Soundness Indicators and Financial Crisis Episodes. Annals of Finance, 10(4), 623-669, https://doi.org/10.1007/s10436-013-0233-6

Kavkler, A., Festić, M. (2010). The Banking Sector in the Baltics. Banks and Bank Systems, 5(3), 87-96. 
Knell, M., Stix, H. (2005). The Income Elasticity of Money Demand: A Meta Analysis of Empirical Results. Journal of Economic Surveys, 19(3), 513-533, https://doi. org/10.1111/j.0950-0804.2005.00257.x

Liu, Y., Yang, W. (2010). What Caused the Soaring Non-Performing Loans in Taiwan from the Late 1990 s to the Beginning of the 2000s? Evidence from Panel Data of Domestic Banks. International Journal of Information and Management Sciences, 21(6), 227-246.

Louzis, D. P., Vouldis, A. T., Metaxas, V. L. (2012). Macroeconomic and Bank-Specific Determinants of Non-Performing Loans in Greece: A Comparative Study of Mortgage, Business and Consumer Loan Portfolios. Journal of Finance and Banking, 36(4), 1012-1027, https://doi.org/10.1016/j.jbankfin.2011.10.012

Love, I., Turk Ariss, R. (2014). Macro-Financial Linkages in Egypt: A Panel Analysis of Economic Shocks and Loan Portfolio Quality. Journal of International Financial Markets, Institutions \& Money, 28(C), 158-181, https://doi.org/10.1016/j.intfin.2013.10.006

Mancka, A. (2012). The Impact of National Currency Instability and the World Financial Crisis in the Credit Risk. The Case of Albania. Journal of Knowledge Management, Economics and Information Technology, 2(1), 1-18.

Marcucci, J., Quagliariello, M. (2008). Is Bank Portfolio Riskiness Procyclical? Evidence from Italy Using a Vector Autoregression. Journal of International Financial Markets, Institutions \& Money, 18(1), 46-63, https://doi.org/10.1016/j.intfin.2006.05.002

Melecký, A., Melecký, M., Šulganová, M. (2015). Non-Performing Loans and the Macroeconomy: Modeling the Systemic Credit Risk in the Czech Republic. Politická ekonomie, 63(8), 921-947, https://doi.org/10.18267/j.polek.1045

Messai, A. S., Jouini, F. (2013). Micro and Macro Determinants of Non-Performing Loans. International Journal of Economics and Financial Issues, 3(4), 852-860.

Moscone, F., Tosetti, E., Canepa, A. (2014). Real Estate Market and Financial Stability in US Metropolitan Areas: A Dynamic Model with Spatial Effects. Regional Science and Urban Economics, 49(C), 129-146, https://doi.org/10.1016/j.regsciurbeco.2014.08.003

Njoroge, L., Kamau, A. W. (2010). Macroeconomic Developments and Banks' Behavior in Kenya: A Panel Data Analysis. Savings and Development, 34(2), 191-217.

Nkusu, M. (2011). Nonperforming Loans and Macrofinancial Vulnerabilities in Advanced Economies. International Monetary Fund. Working Paper No. 11/161, https://doi. org/10.5089/9781455297740.001

Novikov, I. (2012). The Empirical Estimation of the Influence of Credit Risk Determinants in Baltic States' Banking Sector. Journal of Modern Accounting and Auditing, 8(1), 113-127.

Podpiera, R. (2006). Does Compliance with Basel Core Principles Bring any Measurable Benefits? IMF Staff Papers, 53(2), 306-326.

Saba, I., Kouser, R., Azeem, M. (2012). Determinants of Non-Performing Loans: Case of US Banking Sector. The Romanian Economic Journal, 15(44), 141-153.

Salas, V., Saurina, J. (2002). Credit Risk in Two Institutional Regimes: Spanish Commercial and Savings Banks. Journal of Financial Services Research, 22, 203-224.

Shijaku, H., Ceca, K. (2011). A Model for the Credit Risk in Albania Using Banks' Panel Data. Bank of Albania. Working Paper No. 06(29).

Shingjergji, A. (2013). The Impact of Macroeconomic Variables on the Non-Performing Loans in the Albanian Banking System during 2005 - 2012. Academic Journal of Interdisciplinary Studies, 9(2), 335-339, https://doi.org/10.5901/ajis.2013.v2n9p335 
Shu, Ch. (2002). The Impact of Macroeconomic Environment on the Asset Quality on Hong Kong's Banking Sector. Hong Kong Monetary Authority, Research Memorandum No. 20/2002.

Škarica, B. (2014). Determinants of Non-Performing Loans in Central and Eastern European Countries. Financial Theory and Practice, 38(1), 38-59, https://doi.org/10.3326/fintp.38.1.2

Vazquez, F., Tabak, M. B., Souto, M. (2012). A Macro Stress Test Model of Credit Risk for the Brazilian Banking Sector. Journal of Financial Stability, 8(2), 69-83, https://doi. org/10.1016/j.jfs.2011.05.002

Vogiazas, S., Nikolaidou, E. (2011). Investigating the Determinants of Nonperforming Loans in the Romanian Banking System: An Empirical Study with Reference to the Greek Crisis. Economics Research International, 1-13, https://doi.org/10.1155/2011/214689

Vuillemey, G. (2014). Solvency vs. Liquidity. A Decomposition of European Banks' Credit Risk over the Business Cycle. International Economics, 137 (May 2014), 32-51, https://doi. org/10.1016/j.inteco.2013.10.004

Yurdakul, F. (2014). Macroeconomic Modelling of Credit Risk for Banks. Procedia - Social and Behavioral Sciences, 109, 784-793, https://doi.org/10.1016/j.sbspro.2013.12.544

Zeman, J., Jurča, P. (2008). Macro Stress Testing of the Slovak Banking Sector. National Bank of Slovakia. Working Paper No. 1/2008. 